\title{
Forward Osmosis: Temperature Effects By Using Pome as Feed Solution
}

\author{
Hanizah Arifin ${ }^{*}$ \\ Thomas S.Y Choong ${ }^{1,2}$ \\ Chan Kam Rong ${ }^{1}$ \\ Fakhru'l Al-Razi Ahmadun ${ }^{1}$ \\ Luqman Chuah Abdullah ${ }^{1}$ \\ ${ }^{1}$ Faculty of Engineering, Department of Chemical and Environmental Engineering, Universiti \\ Putra Malaysia, 43400, UPM Serdang, Selangor, MALAYSIA. \\ ${ }^{2}$ INTROP, Universiti Putra Malaysia , 43400, UPM Serdang, Selangor, MALAYSIA \\ *e-mail : hanizah.arifin@yahoo.com
}

Forward osmosis (FO) has recently been considered as one of the promising technologies for low energy applications. Factors that influence FO performance are draw solution, types of membrane, membrane orientation, cross flow velocity, module configuration and temperature effect. In this study, the influence of temperature on the performance of FO process has been studied in terms of water flux by using raw POME as feed solution. A higher temperature creates a higher water fluxes at various draw solution concentrations. Percentages of water flux increments for raw POME are between $7 \%$ to $9 \%$ from $25^{\circ} \mathrm{C}$ to $35^{\circ} \mathrm{C}$ and $32 \%$ to $75 \%$ from $25^{\circ} \mathrm{C}$ to $45^{\circ} \mathrm{C}$.

Keywords: Forward Osmosis, POME, temperature, membrane orientation, concentration polarization, water flux

\section{INTRODUCTION}

Palm oil mill effluent (POME) is a brownish acidic liquid that contains high concentration of organic matter and has been identified as the largest source of industrial wastewater pollution in Malaysia (Rupani et al. 2010). It is estimated that about $0.5-0.75$ tonnes of POME is discharged for every tonne of fresh fruit bunch processed (Yacob et al. 2005). POME is generated from various zones during the palm oil production in the mill such as clarification sludge, sterilization condensates and fruit washing water, hydro cyclone drain-off, boiler blows down, reservoir and decanter drain. There is a need for an efficient effluent management system in the palm oil mill to preserve the environment in relation to recent goal of zero-discharge by the authorities. Membrane technology is one of the current technologies that have been introduced in treating POME. Membrane technology is recognised as an efficient, economical and reliable technology that exhibits high potential to be used in the treatment of POME (Ahmad et al. 2009). 
Ahmad et al. (2009) employed ultra filtration and reverse osmosis membrane technology, coupled with coagulation and flocculation as the pre-treatment process, to treat POME and reclaim the drinking water. A water recovery of $78 \%$ water was observed and the quality of water met drinking water standards set by the USEPA (Ahmad et al. 2006). A high quality treated water can be used as boiler feed water (Ahmad et al. 2003) in palm oil process. Several researches such as Yejian et al. (2008), Abdurahman et al. (2011), and Damayanti et al. (2011) investigate about POME treatment with variety of process, such as ultrafiltration, reverse osmosis, membrane anaerobic system, and membrane bioreactor. All these membrane processes are subjected to severe membrane fouling due to high hydraulic pressure involved in the process (Damayanti et al. 2011).

Forward Osmosis (FO) is a promising membrane based separation technology and has been studied in the application of wastewater treatment (Achilli et al. 2009), seawater/brackish

desalination (McCutcheon et al. 2005), power generation (Achilli et al. 2009, Lee et al. 1981), and food processing (Anna et al. 2012). The driving force of the FO is the osmotic pressure differential across the membrane rather than hydraulic pressure differential as in Reverse Osmosis (RO). The osmotic pressure difference encourages a net flow of water molecule through the membrane into the draw solution hence separates the feed water from its solutes effectively. Consequently, the FO process results in concentration of feed stream and dilution of a highly concentrated draw solution, and this diluted draw solution requires further treatment for reuse purposes (Cath et al. 2006). Several unique technological advantages can be achieved from FO process, such as operating at very low or no hydraulic pressure, has high rejection of a wide range contaminants and may have lower membrane fouling propensity than other pressure-driven membrane separation process (Holloway et al. 2007). A lower membrane fouling in FO means that its membrane can have a longer life span. Fouling is more severe in RO as the high hydraulic pressure tends to force all components of a feed stream to be against the membrane surface.

Since the only pressure involved in the FO process is due to the flow resistance in the membrane module which is only a few bars, the FO equipment is simpler and does not encounter many problems on the membrane support (Cath et al., 2006). Fresh water can be produced from the sea using approximately one-tenth of the fuel or electricity required by other desalination methods (Mandell and McGinnis 2011). Nevertheless, there is a lack of investigation on forward osmosis in treating POME. The objective of this paper is to investigate the influence of temperature in treating POME using the FO process. Range of temperature were selected based on the frequent range of temperature been used from other researchers for FO membranes in FO process (Phuntsho et al. 2012, Zhao and Zou 2011). Effects on water fluxes were studied with three different temperatures $\left(25^{\circ} \mathrm{C}, 35^{\circ} \mathrm{C}\right.$ and $\left.45^{\circ} \mathrm{C}\right)$ using a semibatch FO system. 
Hanizah Arifin, Thomas S.Y Choong, Chan Kam Rong, Fakhru'l Al-Razi Ahmadun, and Luqman 33 Chuah Abdullah

\section{METHODOLOGY}

\section{Experimental Set-Up}

A lab scale FO module system was fabricated. The experiment was conducted in FO mode (active layer facing FS).Temperature of samples (feed and draw solutions) were maintained by using water bath (ABAT855, DANIEL). Both FS and DS were heated simultaneously by immersing the glass coil in the water bath as shown in Figure 1 . The membrane module has an effective area of $32 \mathrm{~cm}^{2}$. The membrane unit was customised with channels dimensions of $80 \mathrm{~mm}$ long $\times 40$ $\mathrm{mm}$ wide $\times 2 \mathrm{~mm}$ deep on both sides of the membrane. Two peristaltic pumps (BT600-2J, Longerpump) were used to generate equal flows in closed loop conditions. A digital scale (XB 10200D, Precisa) was used to monitor the weight increment of the DS reservoir for every minute and the weight change was converted to the permeate flux. The digital scale was connected to a computer for data collections. The cross flow velocity was fixed at $22 \mathrm{~cm} / \mathrm{s}$ for the whole experiment.

The experiment was run in a semi-batch mode for about an hour and each test was started with $2 \mathrm{~L}$ of feed and $2 \mathrm{~L}$ of draw solutions. $\mathrm{NaCl}$ solutions ranges from $1 \mathrm{M}$ to $4 \mathrm{M}$ concentration were used as draw solutions. Before raw POME was used as a feed, a baseline measurement with distilled water (DI) was performed. Water

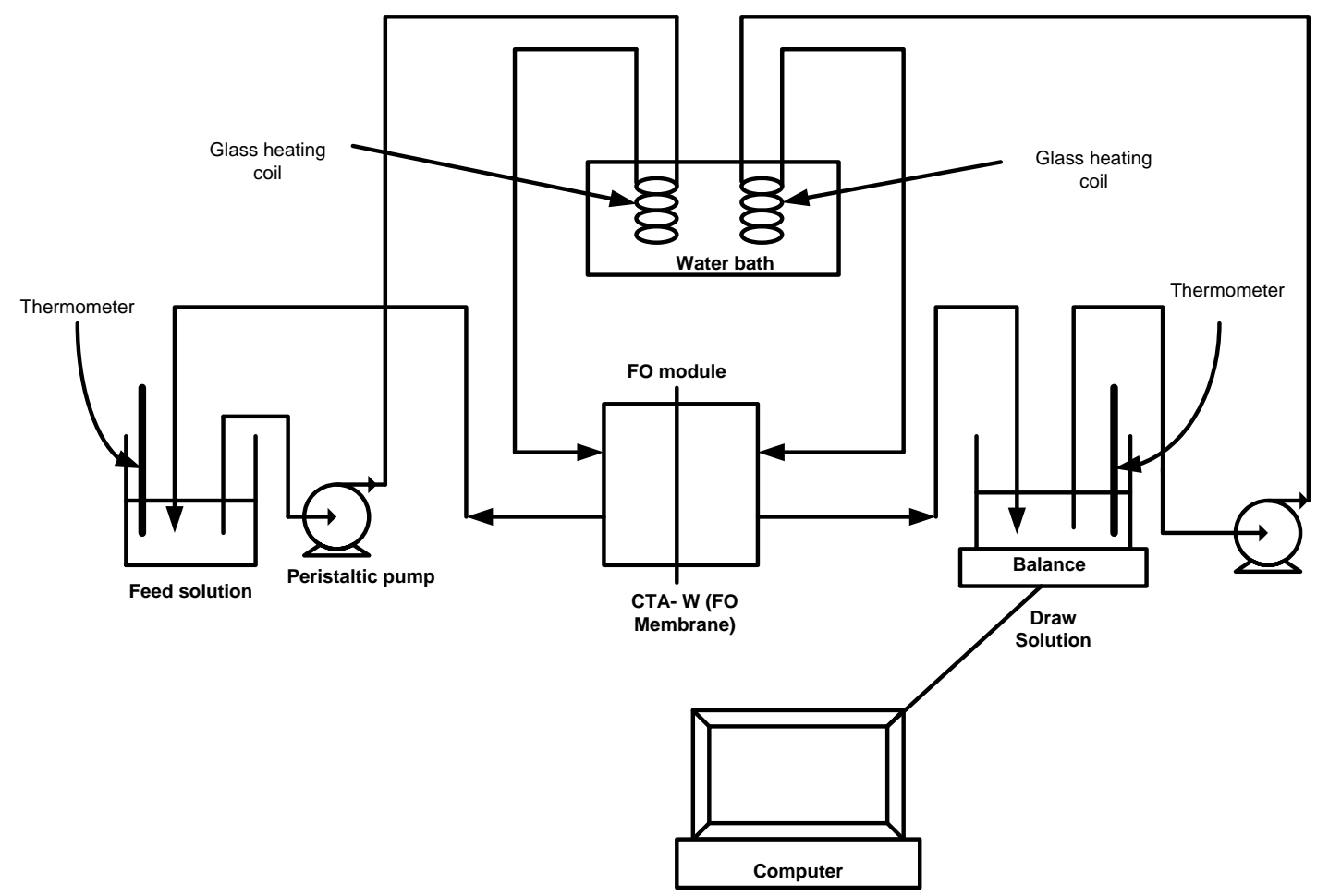

Fig.1: Schematic diagram of a laboratory scale for FO temperature set-up 
flux was determined by measuring the weight change at the DS side during each experiment. Water flux can be calculated by using Eq. (1) (Zhao and Zou, 2011):

$\mathrm{J}_{\mathrm{W}}=\frac{\Delta \text { weight }}{(\text { water density } \times \text { effective area } \times \Delta \text { time })}$

\section{Samples Preparation: Feed and Draw Solutions}

Raw POME from Seri Ulu Langat Palm Oil Mill, Dengkil Selangor was collected as feed sample. In order to test the capability of $\mathrm{FO}$ process to treat $\mathrm{POME}$, only sedimentation and a simple filtration was applied to raw POME with filter paper (ADVANTEC 131, < $5 \mu \mathrm{m}$ retention) to remove the large solids. The raw POME was then used as the feed solution. The characteristics of raw POME after simple filtration and sedimentation process were presented in Table 1.

All chemicals and reagents used in this study were of industrial grade. Sodium chloride $(\mathrm{NaCl}) \quad$ (SystermChemAR) was used to make draw solutions, because it is non toxic, gives high osmotic pressure, cheap and easy to be recovered using RO process. The osmotic pressure of draw solution was calculated using the Van't
Hoff equation:

$\pi=i \Phi \mathrm{MRT}$

where $i$ is the Van't Hoff factor, $M$ is molarity $(\mathrm{mol} / \mathrm{L}), \mathrm{R}$ is gas constant $(0.0836$ $\mathrm{L} \mathrm{atm} / \mathrm{mol} \mathrm{K}), \Phi$ is osmotic coefficient (0.93) and $\mathrm{T}$ is temperature (in Kelvin). The Van't Hoff factor for $\mathrm{NaCl}$ is 2. Stock solution of DS was prepared by dissolving the salts in distilled water and kept for overnight at room temperature before being used in the experiment.

\section{FO Membrane}

A commercial flat sheet FO membrane from Hydration Technologies Inc., CTA-W (cartridge membrane) was used in this experiment. The membrane is made of cellulose triacetate, supported by embedded polyester mesh and has an asymmetric structure. The active layer (AL) is the shiny side of the membrane and the porous layer $(\mathrm{PL})$ is the rough side of the membrane. The membrane was soaked in distilled water for overnight in dark place to remove glycerin which was used to replace the water during shipment. The characteristic of CTA-W (cartridge

Table 1: Characteristics of raw POME with simple filtration and sedimentation process.

\begin{tabular}{lc}
\hline Parameters & Mean \\
\hline $\mathrm{pH}$ & 4.5 \\
Biological Oxygen Demand $\left(\mathrm{BOD}_{5}\right)$ & 14,000 \\
Chemical Oxygen Demand & 25,000 \\
Total Suspended Solids & 850 \\
Ammonia Nitrogen & 24 \\
TDS & 13,000 \\
\hline
\end{tabular}

* All parameters in $\mathrm{mg} / \mathrm{L}$ except $\mathrm{pH}$ 
Table 2: Characteristics of commercial FO membrane substrates (Wei et al. 2011).

\begin{tabular}{ccccc}
\hline $\begin{array}{c}\text { Membrane } \\
\text { sample }\end{array}$ & $\begin{array}{c}\text { Thickness }^{\mathbf{b}} \\
(\boldsymbol{\mu m})\end{array}$ & $\begin{array}{c}\text { Porosity } \\
(\%)\end{array}$ & $\begin{array}{c}\boldsymbol{s} \\
\text { (structural } \\
\text { parameter) } \\
\text { value }(\mathbf{m m})\end{array}$ & $\begin{array}{c}\text { Contact angle } \\
\left({ }^{\circ}\right)\end{array}$ \\
\hline CTA-W $^{\mathbf{a}}$ & $44.7 \pm 14.1(20)$ & $46 \pm 1$ & $1.00 \pm 0.54$ & $69 \pm 2^{\mathrm{C}}$ \\
\hline
\end{tabular}

Notes:

a The cross-sections of TA-W are highly non-uniform due to their woven support. The thickness values given in parentheses are the minimum cross-sectional thickness at the thinnest part of cross-section.

${ }^{b}$ The thickness measured for the commercial FO membranes includes the contribution from the rejection layer. The thickness of the skin layer for CTA-W is on the order of a few micrometers.

c Measured for the bottom surface of membranes.

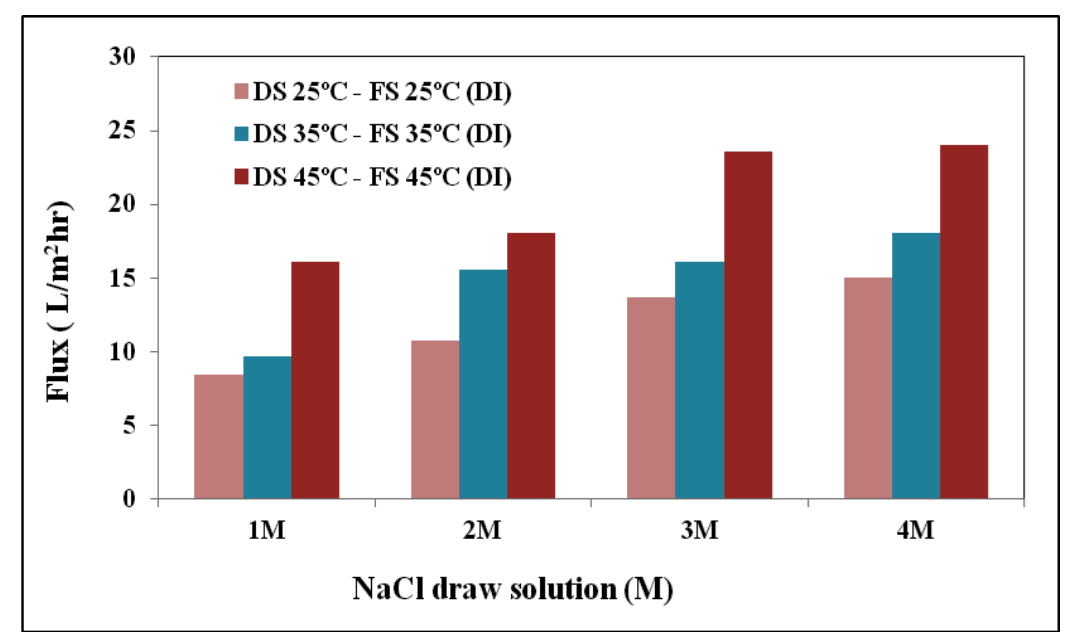

Fig.2: Flux performance of the membrane by using DI as FS and $\mathrm{NaCl}$ as DS.

membrane) was given in Table 2 .

\section{RESULT AND DISCUSSIONS}

Water flux across the membrane was investigated in $A L$ - FS orientation at different operating temperature. This orientation was chosen in order to reduce fouling on the FS side of the membrane. Generally, an increase in temperature increases the water flux as shown in figures 2 and 3. In average, percentage gain of water flux is significantly higher at $45^{\circ} \mathrm{C}$ than $35^{\circ} \mathrm{C}$ for the DI and raw POME.
Based on Figure 2, percentage water flux increased for DI are between $15 \%$ to $45 \%$ from $25^{\circ} \mathrm{C}$ to $35{ }^{\circ} \mathrm{C}$ and $60 \%$ to $91 \%$ from $25^{\circ} \mathrm{C}$ to $45^{\circ} \mathrm{C}$. Compared to raw POME as FS in Figure 3, percentage water flux increment for raw POME was lower than DI. The percentage water flux increments for raw POME are between $7 \%$ to $9 \%$ from $25^{\circ} \mathrm{C}$ to $35^{\circ} \mathrm{C}$ and $32 \%$ to $75 \%$ from $25^{\circ} \mathrm{C}$ to $45^{\circ} \mathrm{C}$.

An increase of water flux can be partially explained by the increase of osmotic pressure of the DS with temperature, as shown in Table 3. 


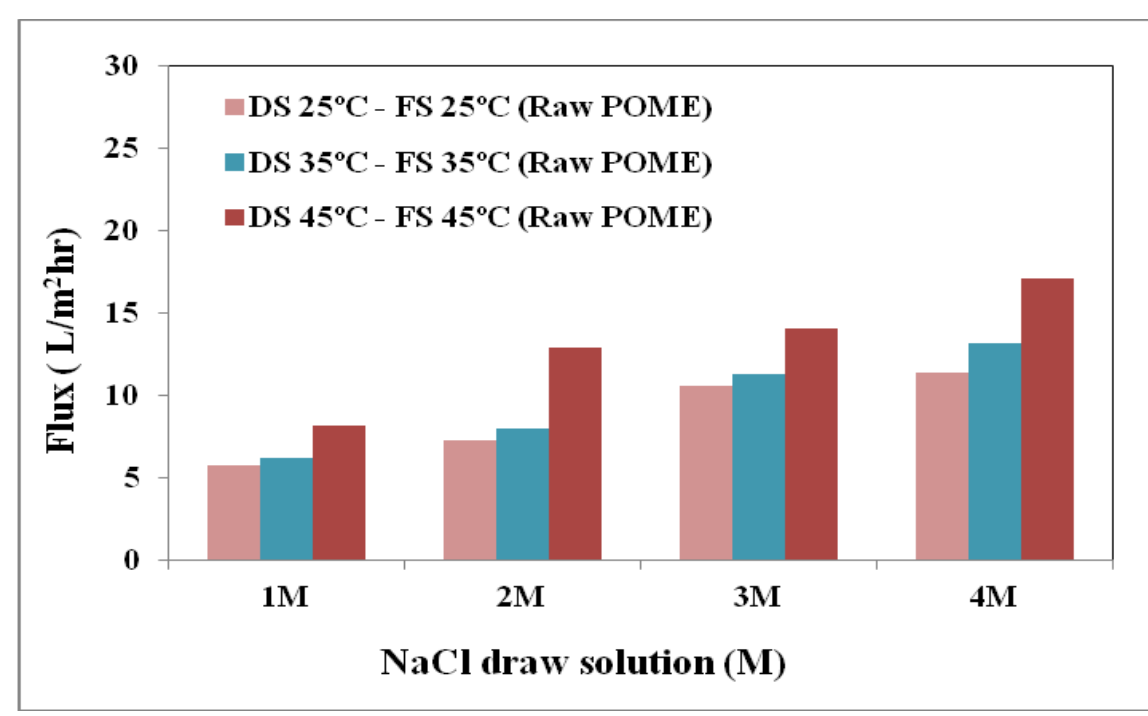

Fig.3: Flux performance of the membrane by using raw POME as $\mathrm{FS}$ and $\mathrm{NaCl}$ as DS.

Table 3: Osmotic pressure of $\mathrm{NaCl}$ solution calculations at the temperature $25^{\circ} \mathrm{C}, 35^{\circ} \mathrm{C}$ and $45^{\circ} \mathrm{C}$.

\begin{tabular}{cccc}
\hline Molarity (M) & \multicolumn{3}{c}{ Osmotic pressure (atm) } \\
\hline & $\mathbf{T}=\mathbf{2 5}^{\circ} \mathbf{C}$ & $\mathbf{T}=\mathbf{3 5}^{\circ} \mathbf{C}$ & $\mathbf{T}=\mathbf{4 5}^{\circ} \mathbf{C}$ \\
\hline $\mathbf{1}$ & 45.51 & $47.03(3.34 \%)$ & $48.56(6.70 \%)$ \\
$\mathbf{3}$ & 91.01 & $94.07(3.36 \%)$ & $97.12(6.71 \%)$ \\
$\mathbf{4}$ & 136.52 & $141.10(3.35 \%)$ & $145.68(6.71 \%)$ \\
& 182.03 & $188.13(3.35 \%)$ & $194.24(6.71 \%)$ \\
\hline
\end{tabular}

* ( ) indicate \% increase in osmotic pressure with reference to $25^{\circ} \mathrm{C}$.

In theory, water flux can be expressed in terms of osmotic pressure as follows (Cath et al., 2006):

$J_{w}=A\left(\pi_{D}-\pi_{F}\right)$

where $J_{w}$ is water flux, $A$ is the water permeability coefficient, $\pi_{\mathrm{D}}$ and $\pi_{\mathrm{F}}$ are the osmotic pressure of draw solution and feed solution. An increase in the osmotic pressure of the DS increases the osmotic pressure difference, thus increases the water flux across the membrane.

Lower increment percentages for raw POME were contributed by the lower net osmotic pressure difference across the membrane. Unlike distilled water as FS, the osmotic pressure for both POME and DS will increase with temperature, resulting in a lower net osmotic pressure. Therefore the percentage increment of water flux of raw POME is not as high as the distilled water.

The increase in osmotic pressure difference alone is not sufficient to explain the high percentage increment of water flux with temperature. During FO mode orientation, two types of concentration polarization occur, which are dilutive ICP and concentrative ECP. Temperature a has profound effect on both ICP and ECP (Zhao and Zou, 2011). 


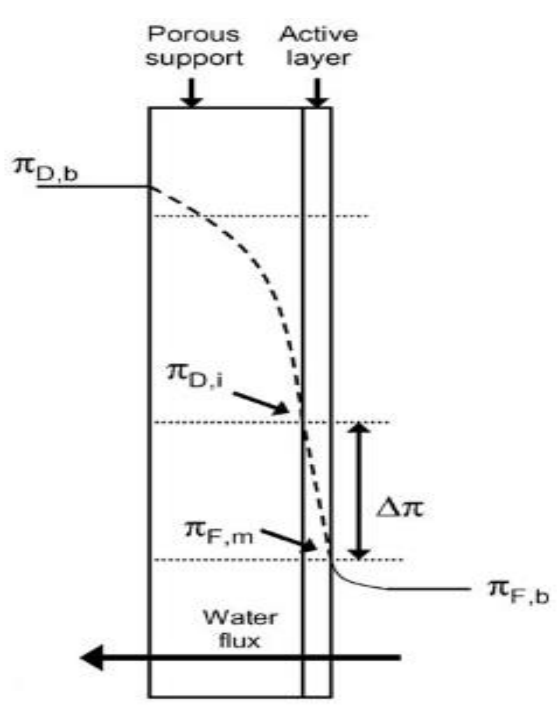

Fig.4: An asymmetric membrane with the porous support layer against the draw solution (FO mode); the profile illustrates dilutive ICP and concentrative ECP. Note $: \pi_{D, b}$ is the bulk draw solution osmotic pressure, $\pi_{D, i}$ is the effective osmotic pressure of the draw solution in FO mode, $\pi_{F, m}$ is the membrane surface osmotic pressure on the feed side, $\pi_{\mathrm{F}, \mathrm{b}}$ is the bulk feed osmotic pressure and $\Delta \pi$ is the effective osmotic driving force (McCutcheon and Elimelech, 2006)

Dilutive ICP occurred when DS is facing the porous layer as shown in Figure 4, because the solute in the DS will penetrate through the porous layer to the surface of active layer and increase the concentration of FS before the water flux can occurred. This situation will decrease the water permeate through the membrane thus reducing the flux performance. But at higher temperature, diffusivity of draw solute will increase and reduce the ICP phenomena at porous layer side thus increase the water flux performance for DI and raw POME as FS.

Unlike distilled water as FS, both ICP and ECP phenomena will occur for raw POME as FS. Concentrative ECP occurred at FS side of membrane when FS is placed against the active layer of the membrane. Water will permeate through the active layer leaving behind the FS solute in higher concentrations. When this situation happens, a higher osmotic driving force must be applied from the DS side in order for water flux to occur. This situation contributes in lowering water flux performance for raw POME at room temperature (as compared to distilled water as DS). At higher temperature, concentrative ECP impact was lessen due to increase of diffusivity of DS at porous layer side and increase the osmotic pressure of the DS.

Another factor that is expected to affect the water flux at higher temperature is the effect of solution viscosity. As viscosity decreases with an increase in temperature, therefore a higher water flux is achieved at higher temperatures as shown by (Zhao and Zou, 2011):

$$
J_{T}=J_{o} \frac{\eta_{o}}{\eta_{T}}
$$


where $J_{0}=$ water flux at reference temperature, $\eta_{0}=$ water viscosity at reference temperature, $J_{T}=$ water flux at a temperature, and $\eta_{T}=$ water viscosity at a temperature.

\section{CONCLUSSIONS}

This study has investigated the effects of temperature towards the performance of FO process in treating POME. Water flux performance was improved with respect to the increase of temperature of FS and DS solutions. The increase in osmotic pressure difference with temperature increases the water flux. The effect of dilutive ICP and concentrative ECP were also lessen at higher temperature, thus increases the water flux performance in the FO process.

\section{Nomenclatures}

\begin{tabular}{|c|c|}
\hline A & $\begin{array}{l}\text { Water permeability } \\
\text { coefficient }\end{array}$ \\
\hline M & Molarity \\
\hline $\mathrm{R}$ & Gas constant \\
\hline $\mathrm{T}$ & Temperature \\
\hline$J_{w}$ & Water flux \\
\hline$J_{0}$ & $\begin{array}{l}\text { Water flux at } \\
\text { reference } \\
\text { temperature }\end{array}$ \\
\hline I & $\begin{array}{l}\text { Water flux at a } \\
\text { temperature }\end{array}$ \\
\hline
\end{tabular}

\section{Greek Symbols}

$\begin{array}{ll}\Pi & : \text { Osmotic pressure } \\ \Phi & : \text { Osmotic coefficient } \\ i & : \text { Van'tt Hoff factor } \\ \eta_{0} & : \text { Water viscosity at } \\ & \begin{array}{l}\text { reference tempe- } \\ \text { rature }\end{array} \\ \eta_{T} & : \text { Water viscosity at a } \\ & \text { temperature }\end{array}$

\begin{tabular}{|c|c|c|}
\hline$\pi_{D}$ & : & $\begin{array}{l}\text { Osmotic pressure } \\
\text { of draw solution }\end{array}$ \\
\hline$\pi_{F}$ & : & $\begin{array}{l}\text { Osmotic pressure } \\
\text { of feed solution }\end{array}$ \\
\hline$\pi_{D, b}$ & : & $\begin{array}{l}\text { Bulk draw solution } \\
\text { osmotic pressure }\end{array}$ \\
\hline$\pi_{D, i}$ & : & $\begin{array}{l}\text { Effective osmotic } \\
\text { pressure of the } \\
\text { draw solution in } \\
\text { FO mode }\end{array}$ \\
\hline$\pi_{\mathrm{F}, \mathrm{m}}$ & : & $\begin{array}{l}\text { Membrane surface } \\
\text { osmotic pressure } \\
\text { on the feed side }\end{array}$ \\
\hline$\pi_{F, b}$ & : & $\begin{array}{l}\text { Bulk feed osmotic } \\
\text { pressure }\end{array}$ \\
\hline$\Delta \pi$ & : & $\begin{array}{l}\text { Effective osmotic } \\
\text { driving force }\end{array}$ \\
\hline
\end{tabular}

\section{Abbreviations}

$\begin{array}{ll}\text { AL } & : \text { Active layer } \\ \text { CTA } & : \text { Cellulose triacetate } \\ \text { CTA-W } & : \text { Cartridge } \\ & : \text { membrane } \\ \text { DI } & : \text { Distilled water } \\ \text { DS } & : \text { Exaw solution } \\ \text { ECP } & \text { concentration } \\ & : \text { polarization } \\ & : \text { Forward osmosis } \\ \text { FO } & : \text { Internal } \\ \text { FS } & \text { concentration } \\ \text { ICP } & \text { polarization } \\ & : \text { Sodium chloride } \\ \mathrm{NaCl} & : \text { Porous layer } \\ \mathrm{PL} & : \text { Palm oil mill } \\ \mathrm{POME} & \text { effluent } \\ \mathrm{RO} & \text { Reverse osmosis }\end{array}$


Hanizah Arifin, Thomas S.Y Choong, Chan Kam Rong, Fakhru'l Al-Razi Ahmadun, and Luqman 39 Chuah Abdullah

\section{REFERENCES}

1. Abdurahman N. H., Rosli Y. M.; and Azhari N. H. (2011). Development of a membrane anaerobic system (MAS) for palm oil mill effluent (POME) treatment. Desalination, 266, 208-212.

2. Achilli A., Cath T. Y. ; and Childress A. E.(2009). Power generation with pressure retarded osmosis: An experimental and theoretical investigation Journal of Membrane Science, 343, 42-52.

3. Achilli A., Cath T. Y., Marchand E. A.; and Childress A. E. (2009). The forward osmosis membrane bioreactor: A low fouling alternative to MBR processes. Desalination, 239, 10-21.

4. Ahmad A. L., Chong M. F.; and Bhatia S. (2009). A comparative study on the membrane based palm oil mill effluent (POME) treatment plant. Journal of Hazard. Materials. 171, 166-174.

5. Ahmad A.L., Chong M.F., Bhantia S.; and Ismail S. (2006). Drinking water reclamation from plam oil mill effluent (POME) using membrane technology. Desalination, 191, 35-44.

6. Ahmad A.L., Ismail S.; and Bhatia S. (2003). Water recycling palm oil mill effluent (POME) using membrane technology. Desalination, 157, 87-95.

7. Anna V. S., Ferreira Marczak L. D.; and Tessaro I. C. (2012). Membrane concentration of liquid foods by forward osmosis: Process and quality view. Journal of Food Engineering, 111, 483-489.

8. Cath T. Y., Childress A. E.; and Elimelech M. (2006). Forward osmosis: Principles applications , and recent developments. Journal of Membrane Science, 281, 70-87.

9. Damayanti A., Ujang Z.; and Salim M. R. (2011). The influenced of PAC, zeolite, and Moringa oleifera as biofouling reducer (BFR) on hybrid membrane bioreactor of palm oil mill effluent (POME). Bioresource Technology, 102, 4341-4346.

10. Holloway R. W., Childress A. E., Dennett K. E.; and Cath T. Y. (2007). Forward osmosis for concentration of anaerobic digester centrate. Water Research, 41, 4005-4014.

11. Lee K. L., Baker R. W.; and Lonsdale H. K. (1981). Membranes for power generation by pressure-retarded osmosis. Journal of Membrane Science, 8, 141-171.

12. Mandell A.; and McGinnis R. (2011). Guest Post: Desalination Realization. greentechmedia.

13. McCutcheon J. R.; and Elimelech M. (2006). Influence of concentrative and dilutive internal concentration polarization on flux behavior in forward osmosis. Journal of Membrane Science, 284, 237-247.

14. McCutcheon J. R., McGinnis R. L.; and Elimelech M. (2005). A novel ammoniacarbon dioxide forward ( direct ) osmosis desalination process. Desalination, 174, 1-11.

15. Phuntsho S., Kyong Shon $H_{\text {., }}$ Vigneswaran S., Kandasamy J., Hong S.; and Lee S. (2012). Influence of temperature and temperature difference in the performance of forward osmosis desalination process. Journal of Membrane Science, 415-416, 734-744. 
16. Rupani P. F., Singh R. P., Ibrahim M. H.; and Esa N. (2010). Review of Current Palm Oil Mill Effluent (POME) Treatment Methods: Vermicomposting as a Sustainable Practice. World Applied Science Journal, 10, 1190-1201.

17. Wei J., Qiu C., Tang C. Y, Wang R.; and Fane A. G. (2011). Synthesis and characterization of flat-sheet thin film composite forward osmosis membranes. Journal of Membrane Science, 372 (1-2), 292-302.

18. Yacob S., Ali M., Shirai Y., Wakisaka M.; and Subash S. (2005). Baseline study of methane emission from open digesting tanks of palm oil mill effluent treatment. Chemosphere, 59, 15751581.

19. Yejian Z., Li Y. A. N., Xiangli Q., Lina C. H. I., Xiangjun N. I. U., Zhijian M. E. I.; and Zhenjia Z. (2008). Integration of biological method and membrane technology in treating palm oil mill effluent. Journal of Environmental Science, 20, 558-564.

20. Zhao S.; and Zou L. (2011). Effects of working temperature on separation performance, membrane scaling and cleaning in forward osmosis desalination. Desalination, 278, 157164. 